\title{
Pengaruh Pengalaman Kerja dan Kompetensi Terhadap Kinerja Karyawan di PT. Naga Samudera
}

\author{
Maria Fransisca dan I Gede Adiputra \\ Program Studi Manajemen Fakultas Ekonomi, Universitas Tarumanagara, Jakarta \\ Email:marmariabieber97@gmail.com
}

\begin{abstract}
The purpose of this study was to determine work experience and competence for employee performance. The method in this study was causal research with a quantitative approach with using questionnaires as a data collection tool. Deep population this research is all employees working in PT. Naga Samudera. The sample size used in this study was 30 respondents. This stud uses SmartPLS version 3.0.0. By using purposive sampling, findings in this study shows that work experience and competence for employee performance have a positive and significant
\end{abstract}

Keywords: working Experience, Competence and Employee Performance

\begin{abstract}
Abstrak:Tujuan dari penelitian adalah untuk mengetahui pengaruh pengalaman kerja dan kompetensi terhadap kinerja karyawan.Metode pada penelitian ini menggunakan penelitian kausal dengan pendekatan kuantitatif dengan menggunakan kuisioner sebagai alat pengumpulan data. Populasi dalam penelitian ini adalah semua karyawan yang bekerja di PT. Naga Samudera di Jakarta. Ukuran sampel yang digunakan pada penelitian ini sebanyak 30 responden. Penelitian ini menggunakan SmartPLS verssi 3.0.0. Dengan menggunakan purposive sampling, temuan pada penelitian ini menunjukkan bahwa pengalaman kerja dan kompetensi terhadap kinerja karyawan berpengaruh positof dan signifikan.
\end{abstract}

Kata Kunci: Pengalaman Kerja, Kompetensi dan Kinerja karyawan

\section{LATAR BELAKANG}

Dalam peradaban manusia saat ini segala aspek kehidupan tidak lepas dari berorganisasi, karena pada kodratnya manusia merupakan makhluk sosial yang cenderung untuk hidup bermasyarakat. Sebuah organisasi dalam menjalankan kegiatan untuk mencapai tujuannya mempunyai beberapa faktor yang berpengaruh. Salah satu dari faktor yang sangat penting dan berpengaruh untuk menggerakan faktor lainnya yaitu sumber daya manusia. Sumber daya manusia merupakan aset organisasi yang paling penting, dan mampu membuat sumber daya organisasi lainnya menjadi bekerja (Simamora, 2006). Dengan demikian, tanpa adanya sumber daya manusia maka sumber daya lainnya akan kurang bermanfaat dalam mencapai tujuan organisasi. Maka dari itu organisasi dituntut untuk dapat mengelola dan mengoptimalkan sumber daya manusia. Menurut Wirawan 
(2009 : 1), sumber daya manusia penting karena berperan untuk menggerakan dan menyinergikan sumber daya lainnya untuk dapat mencapai tujuan organisasi. Untuk mencapai tujuan sebuah organisasi, karyawan akan dituntut untuk dapat memaksimalkan kinerja yang dia miliki.

Sebuah organisasi pasti menginginkan karyawan yang mampu bekerja dengan sungguh-sungguh sesuai dengan kemampuan yang dimiliki agar dapat mencapai hasil kerja yang baik, karena tanpa adanya kinerja yang baik dari seluruh karyawan, maka keberhasilan dalam mencapai tujuan akan sulit untuk dicapai. Pada dasarnya kinerja mencakup sikap mental dan perilaku yang mempunyai pandangan bahwa pekerjaan yang dilakukan pada saat ini harus lebih baik dan berkualitas daripada pelaksanaan pekerjaan pada masa lalu. Seorang karyawan akan merasa mempunyai kebanggaan dan kepuasan tersendiri melalui prestasi yang bisa dicapai berdasarkan kinerja yang diberikannya untuk perusahaan. Karyawan dan organisasi merupakan dua unsur yang saling membutuhkan. Kinerja yang dihasilkan oleh sebuah organisasi merupakan hasil dari kinerja para karyawan dalam orgnasisasi. Keberhasilan seorang karyawan merupakan aktualisasi potensi diri karyawan sekaligus peluang untuk memenuhi kebutuhan hidupnya sedangkan keberhasilan yang di raih oleh organisasi merupakan suatu sarana pertumbuhan dan juga pengembangan. Kinerja merupakan hasil kerja karyawan yang baik secara kualitas maupun kuantitas yang di dasari oleh standar kerja yang telah ditentukan.

Karyawan yang kinerjanya bagus mencerminkan potensi yang dimiliki oleh karyawan tersebut yang kemudian dikembangkan lewat kreativitasnya, senantiasa memberikan sumbangsih yang nyata, kreatif, inovatif serta responsif dalam hubungan dengan orang lain dan penyelesaian persoalan yang ada di dalam sebuah organisasi. Karyawan seperti ini merupakan aset paling berharga bagi sebuah organisasi, karyawan yang bertanggungjawab dan selalu berusaha untuk meningkatkan kualitas diri dalam organisasi tentunya akan dapat mempengaruhi pencapaian produktivitas organisasi. Sejalan dengan pertumbuhannya organisasi dipacu untuk selalu mengembangkan sumber daya manusianya agar karyawan dapat melaksanakan tugasnya secara profesional baik untuk masa sekarang dan juga masa yang akan datang

\section{KAJIAN TEORI}

Menurut Manulang (2004:15), mendefinisikan pengalaman kerja sebagai berikut : “ Pengalaman kerja adalah suatu proses pembentukan pengetahuan atau keterampilan tentang metode suatu pekerjaan karena keterlibatannya dalam pelaksanaan tugas pekerjaan.

Kompetensi oleh Moeheriono (2009:3) adalah sebuah karakteristik yang mendasari seseorang berkaitan dengan efektivitas kinerja individu dalam pekerjaannya atau karakteristik dasar individu yang mempunyai hubungan kausal atau sebab-akibat dengan criteria yang dijadikan sebagai acuan, efektif atau berkinerja prima di tempat kerja atau pada situasi tertentu.

Menurut Edison (2016) kinerja karyawan merupakan hasil dari suatu proses yang mengacu dan diukur selama periode waktu tertentu yang didasari oleh ketentuan atau kesepakatan yang telah ditetapkan sebelumnya.

Kerangka pemikiran dalam penelitian ini, dapat digambarkan sebagai berikut: 
Gambar 1. Kerangka Penelitian

Pengalaman Kerja

Kompetensi

\section{Kinerja Karyawan}

Dengan hipotesis sebagai berikut:

H1 : Terdapat pengaruh positif antara Pengalaman Kerja dengan Kinerja karyawan.

$\mathrm{H} 2$ : Terdapat pengaruh positif antara Kompetensi dengan Kinerja karyawan.

\section{METODOLOGI}

Dalam penelitian ini menggunakan kuisioner sebagai metode dalam pengumpulan data. Desain penelitian kausal akan digunakan untuk menguji keterkaitan antara variabel independen dan variabel dependen. Subyek penelitian ini adalah karyawan tetap PT. Naga Samudera di Jl. Tampak Siring, Ruko Daan Mogot Baru Blok KFJ No.12, Kalideres Jakarta Barat. Penelitian yang dilakukan ini bersifat kuantitatif kausal untuk menguji kebenaran empiris idalam penelitian ini yaitu pengalaman kerja dan kompetensi. Variabel dependen dalam penelitian ini yaitu kompetensi. Metode yang digunakan dalam penelitian ini untuk pengumpulan data menggunakan kuisioner dan metode analisis datanya menggunakan Partial Least Square (PLS).

Penelitian ini menggunakan skala Likert sebagai pemberian skor dari setiap indikator dan penyebaran kuisioner dilakukan secara manual dengan menggunakan Kuisioner.

\section{Hasil Analisis Data}

Dalam deskripsi subjek penelitian ini diuraikan karakteristik responden yang dapat dilihat dari jenis kelamin, usia, pendidikan terakhir dan status perkawinan para responden yang telah mengisi kuesioner.

Outer model merupakan gambaran teori yang dapat menentukan variabel yang bisa diamati dan memungkinkan adanya penelitian validitas.Uji validitas dilakukan dengan cara mengukur validitas konvergen, validitas diskriminan dan AVE.

Tabel 1. Hasil Nilai Average Variance Extracted (AVE)

\begin{tabular}{|c|c|}
\hline Variabel & Average Variance Extracted (AVE) \\
\hline Pengalaman Kerja & 0.652 \\
\hline Kompetensi & 0.629 \\
\hline Kinerja Karyawam & 0.604 \\
\hline
\end{tabular}

*Sumber : olahan data Smart-PLS versi 3.00

Berdasarkan hasil dari average variance extracted (AVE) dalam Tabel 4.10 di atas menunjukkan bahwa nilai average variance extracted (AVE) dalam penelitian ini memiliki hasil yang bagus dimana dalam setiap nilai indikator berada diatas 0,5. Itu bearti nilai average variance extracted (AVE) memenuhi kriteria. Hasil dari semua uji validitas 
didalam outer model dengan menilai convergent validity, discriminant validity, dan nilai AVE memperlihatkan bahwa semua indikator telah valid

Tabel 2. Hasil Nilai Loading Factor

\begin{tabular}{|c|c|c|}
\hline \multicolumn{2}{|r|}{ Indikator } & Loading \\
\hline PK1 & $\begin{array}{l}\text { Lama waktu/masa kerja yang saya miliki dapat membantu saya dalam } \\
\text { bekerja. }\end{array}$ & 0,764 \\
\hline PK2 & $\begin{array}{l}\text { Lama waktu/masa kerja yang saya miliki dapat membuat saya } \\
\text { mengerjakan tugas tanpa adanya kesalahan. }\end{array}$ & 0,764 \\
\hline PK3 & $\begin{array}{l}\text { Pengetahuan dan keterampilan yang saya miliki membantu saya dalam } \\
\text { melakukan pekerjaan. }\end{array}$ & 0,775 \\
\hline PK4 & $\begin{array}{l}\text { Pengetahuan dan keterampilan yang saya miliki masih diatas rata-rata } \\
\text { dari karyawan yang lain. }\end{array}$ & 0,799 \\
\hline PK5 & $\begin{array}{l}\text { Saya dapat menguasai pekerjaan yang diberikan terhadap saya tanpa } \\
\text { bantuan orang lain. }\end{array}$ & 0,813 \\
\hline PK6 & $\begin{array}{l}\text { Saya dapat menguasai peralatan kerja yang disediakan perusahaan } \\
\text { dengan baik. }\end{array}$ & 0,717 \\
\hline PK7 & $\begin{array}{l}\text { Karyawan yang berpengalaman akan melakukan pekerjaannya tanpa } \\
\text { ada keraguan. }\end{array}$ & 0,792 \\
\hline PK8 & $\begin{array}{l}\text { Karyawan yang berpengalaman masih memiliki potensi untuk } \\
\text { melakukan kesalahan. }\end{array}$ & 0,856 \\
\hline PK9 & $\begin{array}{l}\text { Karyawan yang berpengalaman lebih cepat tanggap dalam } \\
\text { menghadapi suatu masalah. }\end{array}$ & 0,910 \\
\hline PK10 & $\begin{array}{l}\text { Karyawan yang berpengalaman dapat mencegah terjadinya suatu } \\
\text { kecelakaan dalam pekerjaan. }\end{array}$ & 0,868 \\
\hline $\mathrm{K} 1$ & $\begin{array}{l}\text { Pekerjaan yang saya lakukan saat ini berdasarkan bakat yang sudah } \\
\text { ada dalam diri saya. }\end{array}$ & 0,765 \\
\hline
\end{tabular}




\begin{tabular}{|c|c|c|}
\hline $\mathrm{K} 2$ & $\begin{array}{l}\text { Pekerjaan yang saya lakukan saat ini memang merupakan pekerjaan } \\
\text { yang saya inginkan. }\end{array}$ & 0,784 \\
\hline K3 & $\begin{array}{l}\text { Saya merasa bahwa saya bertindak melebihi apa yang diharapkan } \\
\text { dalam pekerjaan saya. }\end{array}$ & 0,819 \\
\hline K4 & $\begin{array}{l}\text { Saya bekerja dan melakukan sesuatu tanpa harus menunggu adanya } \\
\text { perintah terlebih dahulu. }\end{array}$ & 0,820 \\
\hline K5 & Saya mampu untuk mengendalikan emosi. & 0,850 \\
\hline K6 & Saya bisa menerima adanya penolakan dari orang lain. & 0,774 \\
\hline K7 & Saya merasa percaya diri dalam setiap pekerjaan yang saya lakukan. & 0,741 \\
\hline K8 & $\begin{array}{l}\text { Saya mampu mengerjakan pekerjaan yang diberikan kepada saya } \\
\text { tanpa ada kesalahan. }\end{array}$ & 0,807 \\
\hline K9 & $\begin{array}{l}\text { Perilaku dan sikap yang baik merupakan salah satu bentuk komitemen } \\
\text { terhadap perusahaan. }\end{array}$ & 0,798 \\
\hline K10 & $\begin{array}{l}\text { Saya akan selalu mementingkan kebutuhan, prioritas dan tujuan } \\
\text { perusahaan. }\end{array}$ & 0,771 \\
\hline KN1 & Saya mampu menyelesaikan pekerjaan dengan tepat waktu. & 0,705 \\
\hline KN2 & Saya bisa menyelesaikan pekerjaan dengan baik dan benar. & 0,805 \\
\hline KN3 & Saya bersedia untuk membantu karyawan lain yang sedang sibuk. & 0,796 \\
\hline KN4 & Saya mampu menyelesaikan pekerjaan dengan cepat. & 0,897 \\
\hline KN5 & $\begin{array}{l}\text { Tanggung jawab terhadap perusahaan merupakan salah satu bentuk } \\
\text { komitmen kerja. }\end{array}$ & 0,806 \\
\hline
\end{tabular}




\begin{tabular}{|c|l|c|}
\hline KN6 & $\begin{array}{l}\text { Saya hadir dan pulang dari tempat kerja sesuai dengan waktu yang } \\
\text { telah ditentukan. }\end{array}$ & 0,742 \\
\hline KN7 & $\begin{array}{l}\text { Saya berusaha untuk meminimalkan kesalahan dalam melakukan } \\
\text { pekerjaan. }\end{array}$ & 0,714 \\
\hline KN8 & $\begin{array}{l}\text { Kinerja yang baik dapat dilihat dari pekerjaan yang di lakukan dengan } \\
\text { akurat tanpa ada kesalahan. }\end{array}$ & 0,747 \\
\hline KN9 & $\begin{array}{l}\text { Tanggung jawab merupakan salah satu bentuk kewajiban yang harus } \\
\text { dimiliki oleh karyawan. }\end{array}$ & 0,771 \\
\hline KN10 & $\begin{array}{l}\text { Saya selalu mengakui setiap kesalahan yang saya lakukan dalam } \\
\text { pekerjaan saya. }\end{array}$ & 0,770 \\
\hline
\end{tabular}

*Sumber : olahan data Smart-PLS versi 3.00

Berdasarkan hasil dari Tabel 2, telah menunjukkan bahwa seluruh indikator memiliki nilai loading factor di atas 0,6 di mana telah memenuhi syarat convergent validity (Hair et al., 2011), sehingga dapat disimpulkan bahwa semua variabel yang ada dalam penelitian ini dapat digunakan.

Tabel 3. Hasil Pengujian Reliabilitas

\begin{tabular}{|c|c|c|}
\hline Variabel & Cronbach's Alpha & Composite Reliability \\
\hline Pengalaman Kerja & 0,940 & 0,949 \\
\hline Kompetensi & 0,935 & 0,944 \\
\hline Kinerja Karyawam & 0,926 & 0,930 \\
\hline
\end{tabular}

*Sumber : olahan data Smart-PLS versi 3.00

Berdasarkan hasil pengujian reliabilitas pada tabel 3, diketahui bahwa variabel di atas memiliki nilai cronbach's alpha dan composite realibility di atas 0,7. Dengan nilai tersebut, maka dapat disimpulkan bawa data pada penelitian ini reliabel karena memenuhi kriteria dengan hasil yang berada di atas 0,7 .

Setelah pengujian outer model (validitas dan reliabilitas), pengolahan data variabelvariabel penelitian dilanjutkan pada tahapan pengujian inner model (model struktural) untuk dapat mengetahui kontribusi dari variabel-variabel independen (X) terhadap variabel-variabel dependen (Y). Kriteria pengujian model struktural yang harus dipenuhi pada penelitian ini yaitu nilai koefisien determinasi $\left(\mathrm{R}^{2}\right)$ dan path coefficients.

Hasil nilai koefisen determinasi $\left(\mathrm{R}^{2}\right)$ pada penelitian ini adalah sebesar 0,834 . Artinya adalah, variasi perubahan variabel dependen sebesar $83,4 \%$ dapat dijelaskan oleh variabel independent. Sedangkan 16,6\% dijelaskan oleh variabel diluar penelitian. 
Tabel 4. Hasil Bootsrapping

\begin{tabular}{|l|c|c|c|}
\hline & Original Sample & T-Statistic & P-Value \\
\hline $\begin{array}{l}\text { Pengalaman Kerja } \rightarrow \\
\text { Kinerja Karyawan }\end{array}$ & 0.479 & 4.302 & 0.000 \\
\hline $\begin{array}{l}\text { Kompetensi } \rightarrow \text { Kinerja } \\
\text { Karyawan }\end{array}$ & 0.559 & 4.823 & 0.000 \\
\hline
\end{tabular}

*Sumber : olahan data Smart-PLS versi 3.00

\section{DISKUSI}

Hasil analisis data validitas dan reliabilitas menunjukkan bahwa semua variabel adalah valid dan reliabel. Valid karena seluruh nilai loading factor untuk semua butir pernyataan pada setiap atribut lebih besar dari 0,7 oleh karena itu convergent validity untuk semua butir pernyataan valid. Serta berdasarkan nilai AVE untuk tiap variabel lebih besar daripada 0,5 sehingga discriminant validity sudah valid. Dan dapat dikatakan reliabel karena nilai alpha-cronbach untuk tiap variabel adalah lebih besar dari 0,7 sehingga dapat disimpulkan bahwa butir pernyataan untuk tiap variabel adalah reliabel.Data yang sudah valid dan reliabel tersebut kemudian diolah kembali dengan menggunakan analisis koefisien determinasi $\mathrm{R}^{2}$. Koefisien determinasi $\mathrm{R}^{2}$ digunakan untuk dapat mengetahui seberapa besar kontribusi variabel pengalaman kerja dan kompetensi terhadap kinerja karyawan. Hasil dari pengujian analisis koefisen determinasi $\mathrm{R}^{2}$ dalam penelitian ini adalah sebesar 0,834 artinya sebesar $83.4 \%$ variasi kinerja karyawan dapat dijelaskan oleh variasi pengalaman kerja dan kompetensi. Sisanya sebesar 16,6\% dijelaskan oleh variabel lain.

Setelah melewati analisis koefisien determinasi $\mathrm{R}^{2}$ maka dilanjutkan dengan pengujian path coefficiens, hasil dari pengujian ini menunjukkan bahwa keseluruhan variabel dalam model ini memiliki path coefficient dengan angka yang positif, mengindikasikan bahwa pengaruh antar variabel adalah searah. Hal ini menunjukkan bahwa jika semakin besar nilai path coefficient pada satu variabel independen terhadap variabel dependen, maka semakin kuat pula pengaruh antar variabel independen terhadap variabel dependen tersebut. Selanjutnya dalam pengujian goodness of fit,pengujian ini dilakukan untuk dapat mengetahui kecocokan dari model yang terdapat dalam penelitian ini. Hasil dari pengujian goodness of fit yaitu sebesar 0.736 , model yang digunakan dalam penelitian ini mempunyai kecocokan yang besar.

Hipotesis yang pertama menunjukkan bahwa variabel pengalaman kerja terbukti berpengaruh secara signifikan terhadap kinerja karyawan karena hasil dari nilai t-statistik kepuasan kerja sebesar 4.302 yang berarti lebih besar dari 1,96 dan p-values sebesar 0,000 yang berarti lebih kecil dari 0,05. Sehingga dapat disimpulkan bahwa pengalaman kerja memiliki pengaruh yang signifikan terhadap kinerja karyawan. Hal tersebut sejalan dengan penelitian yang telah dilakukan Wulandari(2017) Beverly, et al., (2017) dan Karina et al (2017) yang menyimpulkan bahwa pengalaman kerja berpengaruh terhadap kinerja karyawan. Dengan pengalaman kerja, seseorang akan mampu mengembangkan kemampuannya, sehingga diharapkan ia bisa merasa betah untuk tetap bertahan di perusahaan, yang pada akhirnya akan muncul harapan pada dirinya untuk bisa dipromosikan. Seorang karyawan yang mempunyai pengalaman kerja lebih banyak tentunya akan lebih paham mengenai apa yang harus dilakukan ketika menghadapi sebuah 
masalah yang muncul sehingga perusahaan akan lebih mudah mencapai tujuan perusahaan karena didukung oleh para karyawan yang sudah berpengalaman di bidangnya masingmasing.

Kemudian untuk hipotesis kedua dapat menyatakan bahwa kompetensi terbukti memiliki pengaruh yang signifikan terhadap kinerja karyawan dengan tingkat keyakinan 95\%, karena hasil dari nilai t-statistik kompetensi kerja sebesar 4,823 yang berarti lebih besar dari 1,96 dan p-values motivasi kerja sebesar 0,000 yang berarti lebih kecil dari 0,05. Hal tersebut sesuai dengan penelitian yang dilakukan oleh Sujiati, et al.(2017), Tri, et al.(2018), Alex dan Perdana(2015), Reza, et al.(2016), Donny(2015) dan Andi(2017) yang menyimpulkan bahwa variabel kompetensi berpengaruh signifikan terhadapkinerja karyawan. Kompetensi mengacu pada kemampuan yang dimiliki oleh seseorang untuk menghasilkan kinerja yang memuaskan di tempat kerja, termasuk di antaranya yaitu kemampuan untuk mentransfer dan mengaplikasikan keterampilan serta pengetahuan dalam pelaksanaan pekerjaannya.Kompetensi memiliki pengaruh terhadap kinerja karyawan. Semakin tinggi kompetensi yang dimiliki oleh seorang pegawai maka kinerja karyawan juga akan semakin meningkat. Karyawan yang berkompeten biasanya memiliki sikap dan perilaku atau kemauan dan juga kemampuan kerja yang relatif stabil ketika menghadapi situasi di tempat kerja yang terbentuk dari sinergi antara watak, konsep diri, motivasi dan kapasitas pengetahuan sehingga ia mampu dengan cepat dapat mengatasi permasalahan kerja yang sedang dihadapi, melakukan pekerjaan dengan tenang dan juga penuh dengan rasa percaya diri, memandang pekerjaan sebagai suatu kewajiban yang harus dilakukan secara ikhlas dan secara terbuka meningkatkan kualitas diri melalui proses pembelajaran. Hal ini dapat memberikan dorongan yang kuat kepada karyawan agar dapat mengerjakan tugas-tugas yang dibebankan kepadanya dengan efesien dan efektif serta secara psikologis mampu memberikan pengalaman kerja yang bermakna dan rasa tanggung jawab pribadi mengenai hasil-hasil pekerjaan yang dilakukannya.

\section{KESIMPULAN}

Berdasarkan hasil penelitian dari pengujian data dalam penelitian ini menunjukkan bahwa Terdapat pengaruh yang signifikan antara pengalaman kerja terhadap kinerja karyawan PT. Naga Samudera. Semakin banyak pengalaman yang dimiliki oleh seorang karyawan maka akan semakin meningkatkan kinerja karyawan.

Terdapat pengaruh yang signifikan kompetensi terhadap kinerja karyawan PT. Naga Samudera. Artinya jika seorang karyawa memiliki kompetensi yang tinggi akan semakin meningkatkan kinerja karyawan (1) Dalam sebuah penelitian tentunya dapat memiliki beberapa keterbatasan, begitu pula dalam penelitian ini. Keterbatasan dari penelitian ini dikarenakan: Perusahaan dapat meningkatkan kinerja karyawan dengan memberikan pelatihan-pelatihan yang memadai terhadap karyawan karena dengan pelatihan akan meningkatkan pengalaman karyawan dalam bekerja yang pada akhirnya akan meningkatkan karyawan tersebut. Selain itu dalam proses perekrutan atau penerimaan tenaga kerja sebaiknyapimpinan perusahaan memperhatikan pengalaman kerja dari calon tenagakerja. Sebab berdasarkan penelitian ini diketahui bahwa pengalaman kerjamemiliki pengaruh terhadap kinerja karyawan (2) Disarankan kepada pimpinan perusahaan agar dapat meningkatkan kompetensi karyawan, yaitu dengan dengan melakukan diklat guna dapat meningkatkan pengetahuan dan keterampilan kepada karyawan di masa yang akan datang. Disarankan pula agar dalam meningkatkan kinerja karyawan maka perlunya 
memperhatikan masalah kompetensi karyawan, khususnya yang berkaitan dengan keterampilan kerja pegawai dalam menangani setiap pekerjaan yang diberikan. (3) Bagi peneliti lain, disarankan untuk melakukan penambahan variabel lain yang juga diperkirakan dapat memberikan pengaruh terhadap kinerja karyawan seperti kompensasi, intsentif, lingkungan kerja dan budaya organisasi.

\section{DAFTAR PUSTAKA}

Edison, Emron, Yohny Anwar dan Imas Komariyah. (2016). Manajemen Sumber Daya Manusia. Bandung : Alfabeta.

Manullang, M dan Marihot A.M.H Manullang. (2004). Manajemen Personalia. Yogyakarta : Gajah Mada University Press.

Moeheriono. (2009). Pengukuran Kinerja Berbasis Kompetensi. Bogor : Penerbit Ghalia Indonesia.

Simamora, Henry. ( 2006). Manajemen Sumber Daya Manusia, Edisi 2, STIE Y YPN. Yogyakarta.

Wirawan, (2009). Evaluasi Kinerja Sumber Daya Manusia Teori Aplikasi dan Penelitian. Jakarta. Penerbit: Salemba Empat. 